\title{
Stability Indicating ReVERSE PHASE HPLC MeThOD DEVELOPMENT AND VALIDATION FOR ESTIMATION OF CHLORAMPHENICOL AND FLURBIPROFEN SODIUM IN Pharmaceutical Dosage Form
}

\author{
Nisha Parikh*, Neha Patel and Nidhi Patel \\ Department of Quality Assurance, Arihant School of Pharmacy and Bio-Research Institute, Adalaj, \\ Gandhinagar-382421, Gujarat, India \\ *E-mail: parikhnisha83@gmail.com \\ Tel.: +919924341133.
}

Received: Jan 25, 2019 / Revised: Apr 24, 2019 / Accepted: Apr 25, 2019

\begin{abstract}
A simple, precise and rapid stability indicating RP-HPLC method is developed for the estimation of Chloramphenicol and Flurbiprofen sodium in formulation of Flubichlor eye drops in presence of degradation products. The separation was achieved using mobile phase Acetonitrile: Water: Glacial Acetic Acid (50:49:1 v/v/v) at flow rate of $1.0 \mathrm{ml} / \mathrm{min}$. The effluent was monitored at $247 \mathrm{~nm}$. The retention time of Chloramphenicol and Flurbiprofen sodium was found to be 1.980 and $7.727 \mathrm{~min}$ respectively. The total run time was $10.0 \mathrm{~min}$ within which two active compounds and their degradation products were separated. Acid, alkali, peroxide, thermal and photo degradation was carried out. The method was found to be specific enough to separate degradation products from main analytes. The described method was validated with respect to system suitability, specificity, linearity, accuracy, precision and robustness. Result of each parameter was met with its acceptance criteria. Method was found to be fast and is suitable for high-throughput analysis of the two drugs in presence of degradation products.
\end{abstract}

Key words: RP-HPLC, Chloramphenicol, Flurbiprofen sodium, Stability Indicating method.

\section{INTRODUCTION}

Chloramphenicol (CHLO) is a broad-spectrum antibiotic which acts by inhibiting protein synthesis. It is primarily bacteriostatic, having nitrobenzene substitution and is active against gram-positive and negative bacteria. It is used in the treatment of bacterial conjunctivitis and preferred drug for endophthalmitis caused by sensitive organisms. Flurbiprofen (FLUR), a nonsteroidal anti-inflammatory drug, is a propionic acid derivative which acts by inhibiting the bodily synthesis of prostaglandins. It is used topically prior to ocular surgery to prevent or reduce intraoperative miosis. Combination of Chloramphenicol and Flurbiprofen is used in postoperative condition to reduce pain, swelling and eye infection, anti-infective and anti-septic, in bacterial conjunctivitis and is available as eye drops. The structures of Chloramphenicol and Flurbiprofen sodium are given in Figure 1.

Literature survey reveals that RP-HPLC (Koup et al 1978; Li et al 2002; Wang et al 2001; Rimawi and Kharoaf, 2011; Adewuyi et al 2011; Hossain et al 2011) and LC-MS (Tamosiunas et al 2006; Pan et al 2006) stability indicating method (Katakam and Sireesh, 2012; Katakam et al 2012) for estimation of chloramphenicol alone or in combination with other drugs from pharmaceutical formulation have been developed as well as spectrophotometric 
<smiles>O=C(N[C@H](CO)[C@@H](O)c1ccc([N+](=O)[O-])cc1)C(Cl)Cl</smiles>

(a)<smiles>CC(C(=O)O)c1ccc(-c2ccccc2)c(F)c1</smiles>

(b)

Fig. 1. Structures of (a) Chloramphenicol and (b) Flurbiprofen sodium

(Sanjeev and Jadhav, 2002; Chauhan et al 2007; Patel et al 2013), TLC (Jagathi et al 2011), RPHPLC (Akhlaq et al 2011; Rajani et al 2014), high performance thin layer chromatography (Dhavse et al 1997), stability indicating method (Modi and Chaudhary, 2017) for estimation of Chloramphenicol and Flurbiprofen sodium. The aim of the present work is to develop and validate a new simple, rapid, selective, costeffective and stability indicating RP-HPLC method for simultaneous determination of Chloramphenicol and Flurbiprofen sodium in a pharmaceutical formulation.

\section{MATERIALS AND METHODS \\ Chemicals and Reagents}

Analytical pure samples of Chloramphenicol (Swiss Parenteral Pvt. Limited, Gujarat, India) and Flurbiprofen Sodium (Sun Pharmaceuticals Industries Limited, Ankleshwar, Gujarat, India) were used in the study. The pharmaceutical dosage form used in the study was Flubichlor (Entod Pharmaceuticals Limited, Mumbai, India) procured from the local market and labeled to contain $0.5 \% \mathrm{w} / \mathrm{v}$ Chloramphenicol and $0.03 \%$ $w / v$ Flurbiprofen sodium. All solvents and reagents used in the study were of AR grade.

\section{Instrumentation}

A HPLC system consists of Agilent 1260 ALS Autosampler (Agilent, United States) with microlitre syringe $(20 \mu \mathrm{L})$ on symmetry C18 column $(150 \mathrm{~mm} \times 4.6 \mathrm{~mm}$ with $5 \mu \mathrm{m}$ thickness, waters, Germany). Agilent PDA 1260 detector (Agilent, United States) with EZ chrome software and Shimadzu Aux 120 (Gottingen, Germany) analytical balance were used in study.

\section{Preparation of standard solutions}

Preparation of standard solution of Chloramphenicol

Chloramphenicol (50 mg) was dissolved in 50 $\mathrm{mL}$ of diluent to obtain a concentration of 1000 $\mu \mathrm{g} / \mathrm{mL}$. From, the standard stock solution, $1 \mathrm{~mL}$ was suitably diluted to $10 \mathrm{~mL}$ with diluent to obtain the working standard solutions of 100 $\mu \mathrm{g} / \mathrm{mL}$.

Preparation of standard solution of Flurbiprofen sodium

Flurbiprofen sodium (50 mg) was dissolved in $50 \mathrm{~mL}$ of diluents to obtain a concentration of $1000 \mu \mathrm{g} / \mathrm{mL}$. From, the standard stock solution, $1 \mathrm{~mL}$ was suitably diluted to $10 \mathrm{~mL}$ with diluent to obtain the working standard solutions of 100 $\mu \mathrm{g} / \mathrm{mL}$.

\section{Preparation of sample solution}

One $\mathrm{ml}$ from eye drops (Flubichlor, labeled to contain $0.5 \% \mathrm{w} / \mathrm{v}$ Chloramphenicol and $0.03 \%$ $w / v$ Flurbiprofen sodium) was transferred to a specified $10 \mathrm{ml}$ of volumetric flask and dissolved in $5 \mathrm{~mL}$ of diluent, sonicated for $10 \mathrm{~min}$ and diluted up to mark. Then $2.0 \mathrm{~mL}$ of the solution was diluted to $10 \mathrm{~mL}$ to obtain the final concentration of $100 \mu \mathrm{g} / \mathrm{mL}$ Chloramphenicol and $6 \mu \mathrm{g} / \mathrm{mL}$ Flurbiprofen sodium.

\section{Optimized chromatographic conditions}

About $20 \mu \mathrm{L}$ of the blank solution or standard solution was injected into symmetry, C18 (150 $\mathrm{mm} \times 4.6 \mathrm{~mm} \times 5.0 \mu$ ) column maintained at a temperature of $25 \pm 2{ }^{\circ} \mathrm{C}$. The components were separated by using mobile phase of acetonitrile:water:glacial acetic acid in the ratio $(50: 49: 1 \mathrm{v} / \mathrm{v} / \mathrm{v})$ at a flow rate $1.0 \mathrm{~mL} / \mathrm{min}$ under an isocratic mode. The components were detected at a wavelength $247 \mathrm{~nm}$ using photodiode array (PDA) detector and all measurements were operated by EZchrom software.

\section{Method validation}

The method was validated in compliance with ICH guidelines (ICH, 1996).

\section{System suitability studies}

System suitability was established by injecting six replicates of a standard solution of Chloramphenicol and Flurbiprofen sodium and 
the \% RSD of retention time, asymmetry and theoretical plates were determined.

\section{Linearity}

A linear relationship between peak area and concentration of the drugs was evaluated over the concentration range expressed in $\mu \mathrm{g} / \mathrm{mL}$ by making five replicate measurements in the concentrations range of $50-300 \mu \mathrm{g} / \mathrm{mL}$ for chloramphenicol and $6-18 \mu \mathrm{g} / \mathrm{mL}$ for flurbiprofen sodium, respectively.

\section{Precision}

The repeatability of the method was checked by analyzing $(n=6)$ solutions of Chloramphenicol (200 $\mu \mathrm{g} / \mathrm{mL}$ each) and Flurbiprofen sodium (12 $\mu \mathrm{g} / \mathrm{mL}$ ) the response were recorded. The intraday (3 times on the same day) and inter-day (3 different days over a period of 1 week) precisions of the proposed method were checked by measuring the responses for 3 different concentration of $100,150,200 \mu \mathrm{g} / \mathrm{mL}$ for chloramphenicol and 6.0, 9.0, $12.0 \mu \mathrm{g} / \mathrm{mL}$ for Flurbiprofen sodium .The solution was injected and peak area was obtained. The $\%$ assay values were calculated. The $\%$ RSD was reported.

\section{Recovery studies}

Recovery studies were carried out by spiking three different known amounts of the standard substances to the drug product (standard addition method). Hence, 50, 100 and 150 $\mu \mathrm{g} / \mathrm{mL}$ of Chloramphenicol and 3, 6, $9 \mu \mathrm{g} / \mathrm{mL}$ of Flurbiprofen sodium were spiked to the dosage form that contained $100 \mu \mathrm{g} / \mathrm{mL}$ of Chloramphenicol and $6 \mu \mathrm{g} / \mathrm{mL}$ of Flurbiprofen sodium, respectively, after sample dilution.

\section{Limit of detection (LOD) and limit of quantitation} (LOQ)

The limit of detection (LOD) and limit of quantitation (LOQ) was calculated by the equation:

LOD $=3.3 \times($ SD $/$ Slope $)$

$\mathrm{LOQ}=10 \times(\mathrm{SD} /$ Slope $)$

where:

SD = Standard deviation of the Y-intercepts of the calibration curve

Slope $=$ Mean slope of the calibration curve

\section{Robustness}

The effect of deliberate variations in method parameters like the composition of the mobile phase, flow rate of mobile phase on chromatogram was evaluated in this study. The effect of these changes on peak areas was evaluated by calculating the relative standard deviations (RSD) for each parameter.

\section{Analysis of marketed formulation}

The eye drops sample solutions were prepared as per section 2.4. Suitable working sample solutions $(20 \mu \mathrm{L})$ containing Chloramphenicol and Flurbiprofen sodium in the concentration ratio of $1: 16.66(100 \mu \mathrm{g} / \mathrm{mL}$ and $6 \mu \mathrm{g} / \mathrm{mL}$ of Chloramphenicol and Flurbiprofen sodium, respectively) were prepared, applied on HPLC column and analyzed under the optimized chromatographic conditions.

\section{Stability studies}

To evaluate the stability indicating properties of the developed HPLC method, forced degradation studies were carried out in accordance with the ICH guidelines. The standard drugs were subjected to acid, base, oxidation, thermal degradation and photo-degradation studies.

\section{Stability stock solution}

Accurately weighed $10 \mathrm{mg}$ Chloramphenicol and $6 \mathrm{mg}$ of Flurbiprofen sodium was diluted to 100 $\mathrm{mL}$ with diluent to obtain $100 \mu \mathrm{g} / \mathrm{mL}$ of Chloramphenicol and $60 \mu \mathrm{g} / \mathrm{mL}$ Flurbiprofen sodium.

\section{Acid-induced degradation study}

For acid degradation study, $\mathrm{HCl}(0.01 \mathrm{M}, 1 \mathrm{~mL})$ was added separately to $1 \mathrm{~mL}$ stability stock solution of Chloramphenicol and of Flurbiprofen sodium in $10 \mathrm{~mL}$ volumetric flasks. The mixtures were refluxed at $60{ }^{\circ} \mathrm{C}$ for $6 \mathrm{~h}$ and the volume was made up with diluent $(100 \mu \mathrm{g} / \mathrm{mL}$ of Chloramphenicol and $6 \mu \mathrm{g} / \mathrm{mL}$ Flurbiprofen sodium). The forced degradation was performed in the dark to exclude the possible degradation effect of light. The resulting solution was applied to HPLC column and the chromatograms were run as described above.

\section{Base-induced degradation study}

For the base degradation study, $\mathrm{NaOH}(0.01 \mathrm{M}, 1$ $\mathrm{mL}$ ) was added separately to $1 \mathrm{~mL}$ stability stock solution of Chloramphenicol and of Flurbiprofen sodium in $10 \mathrm{~mL}$ volumetric flasks. The mixtures were refluxed at $60{ }^{\circ} \mathrm{C}$ for $24 \mathrm{~h}$ and the volume was made up with diluent $(100 \mu \mathrm{g} / \mathrm{mL}$ of Chloramphenicol and $6 \mu \mathrm{g} / \mathrm{mL}$ Flurbiprofen sodium). The samples were then applied and analyzed as described in the acid-induced degradation study. 
Hydrogen peroxide-induced (oxidation) degradation study

$\mathrm{H}_{2} \mathrm{O}_{2}(3 \% \mathrm{w} / \mathrm{v}, 1 \mathrm{~mL})$ was added separately to 1 $\mathrm{mL}$ stability stock solution of Chloramphenicol and of Flurbiprofen sodium in $10 \mathrm{~mL}$ volumetric flasks. The mixtures were refluxed at $60{ }^{\circ} \mathrm{C}$ for 4 $\mathrm{h}$ and the volume was made up with diluent (100 $\mu \mathrm{g} / \mathrm{mL}$ of Chloramphenicol and $6 \mu \mathrm{g} / \mathrm{mL}$ Flurbiprofen sodium).The samples were then applied and analyzed as described in acidinduced degradation study.

\section{Thermal degradation study}

For dry heat degradation study, the standard powder drugs were placed in an oven at $60{ }^{\circ} \mathrm{C}$ for $6 \mathrm{~h}$. Appropriate dilutions were prepared in methanol and then analyzed under the optimized chromatographic conditions.

\section{Photo-degradation study}

For the photo-degradation study, the standard powder drugs were exposed to UV light in a photo-stability chamber for $4 \mathrm{~h}$. appropriate dilutions were prepared in methanol and then analyzed under the optimized chromatographic conditions.

\section{RESULTS AND DISCUSSION HPLC method optimization}

For the selection of appropriate mobile phase for the effective separation of Chloramphenicol and Flurbiprofen sodium, several runs were made by using mobile phases containing solvents of varying polarity, at different concentration levels. Different mobile phase systems like at different concentration levels were tried. Among the different mobile phase combinations employed, the mobile phase consisting of acetonitrile: water: glacial acetic acid in the ratio of (50:49:1) $v / v / v$ gave the best resolution with sharp well-defined peaks with $R_{t}$ values of 1.980 $\min \pm 0.02$ and $7.727 \quad \min \pm 0.02$ for Chloramphenicol and Flurbiprofen sodium, respectively.

For the selection of analytical wavelength for the quantification of the drugs, their overlain spectra were obtained on the HPLC instrument. Both Chloramphenicol and Flurbiprofen sodium exhibited strong absorbance at about $247 \mathrm{~nm}$ which was selected as the analytical wavelength for further analysis.

\section{Method validation}

System-suitability parameters

The results of system-suitability test parameters were listed in Table 1. \% RSD for all parameter was found to be less than $2 \%$ which indicates system is suitable.

Table 1. Results of system suitability test parameters $(n=6)$

\begin{tabular}{|c|c|c|c|c|c|c|}
\hline No. & $\begin{array}{l}\text { Retention } \\
\text { time (min) }\end{array}$ & Asymmetry & $\begin{array}{c}\text { Theoretical } \\
\text { plates }\end{array}$ & $\begin{array}{c}\text { Retention } \\
\text { time (min) }\end{array}$ & Asymmetry & $\begin{array}{l}\text { Theoretical } \\
\text { plates }\end{array}$ \\
\hline & \multicolumn{3}{|c|}{ CHLO } & \multicolumn{3}{|c|}{ FLUR } \\
\hline 1 & 1.98 & 1.61 & 4413 & 7.72 & 1.56 & 5213 \\
\hline 2 & 1.97 & 1.62 & 4453 & 7.71 & 1.54 & 5221 \\
\hline 3 & 1.95 & 1.59 & 4408 & 7.81 & 1.56 & 5261 \\
\hline 4 & 1.95 & 1.60 & 4465 & 7.73 & 1.55 & 5289 \\
\hline 5 & 1.99 & 1.61 & 4467 & 7.73 & 1.53 & 5289 \\
\hline 6 & 1.98 & 1.62 & 4468 & 7.74 & 1.52 & 5278 \\
\hline Mean & 1.97 & 1.60 & 4445.66 & 7.75 & 1.54 & 5260 \\
\hline SD & 0.01 & 0.011 & 27.81 & 0.04 & 0.01 & 35.60 \\
\hline$\%$ RSD & 0.94 & 0.68 & 0.62 & 0.57 & 0.64 & 0.69 \\
\hline
\end{tabular}

\section{Linearity}

Linearity is the property of a mathematical relationship or function which means that it can be graphically represented as a straight line. Calibration graphs were constructed in the concentration range of $50-250 \mu \mathrm{g} / \mathrm{mL}$ for Chloramphenicol and 3-18 $\mu \mathrm{g} / \mathrm{mL}$ for Flurbiprofen sodium. The correlation coefficients, $y$-intercepts, and slopes of the regression lines of the two drugs were calculated and are presented in Table 2.

\section{Specificity}

Specificity of the proposed method was determined by injecting about $20 \mu \mathrm{L}$ of the blank or working standard of Chloramphenicol and Flurbiprofen sodium or sample solution into the HPLC system and chromatograms were recorded under the optimized chromatographic conditions as shown in Figure 2, 3. The chromatograms of standard Chloramphenicol and Flurbiprofen sodium and sample showed 
that two peaks with $100 \%$ peak area at retention time $1.980 \mathrm{~min}$ and $7.727 \mathrm{~min}$ for
Chloramphenicol and Flurbiprofen sodium respectively.

Table 2. Linear regression data for the calibration curve $(n=5)$

\begin{tabular}{|c|c|c|}
\hline Parameters & CHLO & FLUR \\
\hline Linearity range & $50-300 \mu \mathrm{g} / \mathrm{mL}$ & $6-18 \mu \mathrm{g} / \mathrm{mL}$ \\
\hline Linearity regression equation & $\mathrm{y}=33,884.330 \mathrm{x}-396,374.467$ & $\mathrm{y}=192,920.438 \mathrm{x}-225,416.933$ \\
\hline Slope \pm SD & $33,884.330$ & $192,920.438$ \\
\hline Intercept \pm SD & $396,374.467$ & $225,416.933$ \\
\hline Correlation coefficient $\left(\mathrm{r}^{2}\right)$ & 0.999 & 0.998 \\
\hline
\end{tabular}

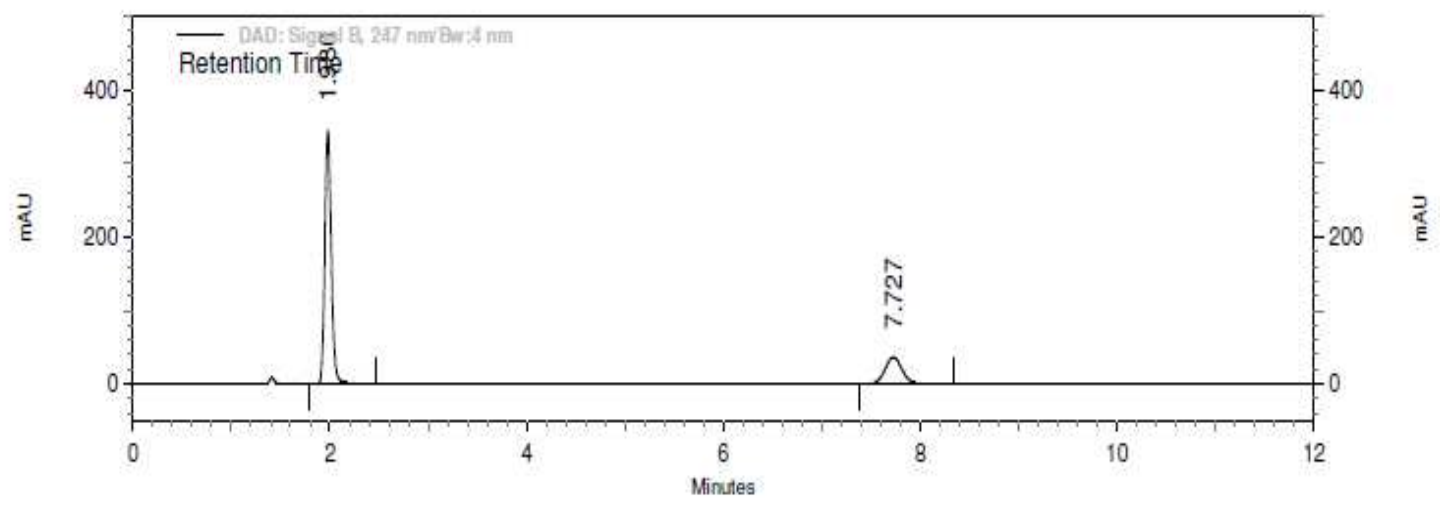

Fig. 2. RP-HPLC chromatogram of standard Chloramphenicol (100 $\mu \mathrm{g} / \mathrm{mL})$ and Flurbiprofen $(6 \mu \mathrm{g} / \mathrm{mL})$

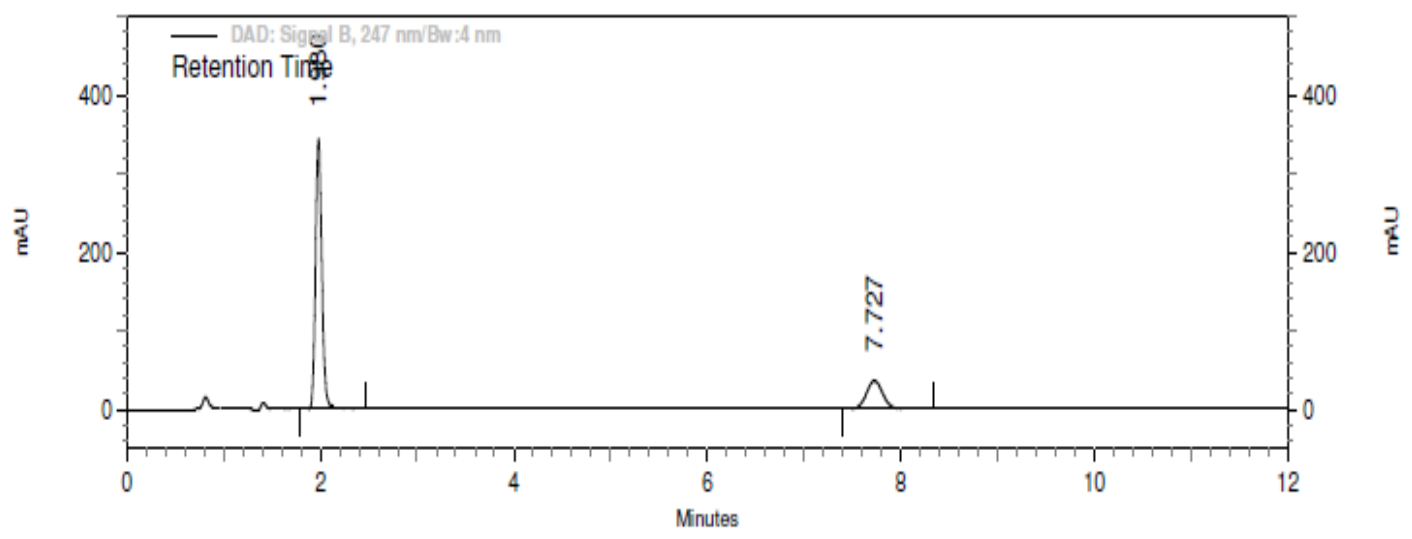

Fig. 3. RP-HPLC chromatogram of sample Chloramphenicol $(100 \mu \mathrm{g} / \mathrm{mL})$ and Flurbiprofen $(6 \mu \mathrm{g} / \mathrm{mL})$

Precision

Repeatability and intermediate precision of the developed method were expressed in terms of relative standard deviation (RSD) of the peak area. The results showed that the repeatability solutions of Chloramphenicol $(200 \mu \mathrm{g} / \mathrm{mL}$ each $)$ and Flurbiprofen sodium $(12 \mu \mathrm{g} / \mathrm{mL})$ and interday variation of the results at a concentration of $100,150,200 \mu \mathrm{g} / \mathrm{mL}$ for Chloramphenicol and 6, 9, $12 \mu \mathrm{g} / \mathrm{mL}$ for Flurbiprofen sodium were within the acceptable range. The results of repeatability are as shown in Table 3. \% RSD for repeatability of Chloramphenicol and Flurbiprofen sodium was 0.007 and 0.33 respectively. The results of intra-day precision and inter-day precision are shown in Table 4. The \% RSD for intra-day precision and inter-day precision were found to be less than two, which indicated the method precision.

\section{Accuracy/recovery studies}

The recovery studies were carried out at $50 \%$, 
$100 \%$ and $150 \%$ of the test concentration. The percentage recovery of Chloramphenicol and Flurbiprofen sodium at all the three levels was found to be satisfactory (Table 5). For
Chloramphenicol, the \% recovery was found between $98.83 \%$ and $100.33 \%$ and for Flurbiprofen sodium between $99.92 \%$ and $100.37 \%$, respectively.

Table 3. Results of repeatability $(n=6)$

\begin{tabular}{|c|c|c|c|c|c|c|c|c|c|}
\hline Drug & Conc. & 1 & 2 & 3 & 4 & 5 & 6 & SD & $\%$ RSD \\
\hline CHLO & 200 & 6409454 & 6410500 & 6409648 & 6410325 & 6410216 & 6409545 & 450.5779 & 0.007029 \\
\hline FLUR & 12 & 2096215 & 2089541 & 2095481 & 2088195 & 2098125 & 2079581 & 6902.4 & 0.33007 \\
\hline
\end{tabular}

Table 4. Intraday and Interday precision of the method $(n=3)$

\begin{tabular}{|c|c|c|c|c|c|c|}
\hline Drug & \multicolumn{7}{c|}{ CHLO } & \multicolumn{3}{c|}{ FLUR } \\
\hline Conc. $(\boldsymbol{\mu g} / \mathbf{m l})$ & 100 & 150 & 200 & 6 & 9 & 12 \\
\hline \multicolumn{7}{|c|}{ Intraday precision } \\
\hline Mean peak area & 2982720 & 4675089 & 6410500 & 944350 & 1566497 & 2096215 \\
\hline \pm S.D. & 12801.580 & 15069.603 & 17844.531 & 2382.142 & 5198.589 & 4766.628 \\
\hline \% R.S.D & 0.42 & 0.32 & 0.27 & 0.29 & 0.34 & 0.22 \\
\hline \multicolumn{7}{|c|}{ Interday precision } \\
\hline Mean peak area & 2970268 & 4658494 & 6434258 & 946695.7 & 1512253 & 2086350 \\
\hline \pm S.D. & 16318.930 & 28618.000 & 32525.44 & 4567.028 & 10301.580 & 7339.803 \\
\hline \% R.S.D & 0.54 & 0.61 & 0.50 & 0.48 & 0.68 & 0.44 \\
\hline
\end{tabular}

Table 5. Recovery as accuracy studies of the proposed HPLC method ( $\mathrm{n}=3$ )

\begin{tabular}{|c|c|c|c|c|c|c|}
\hline Drug & Spike level \% & Taken & Added & Found & Mean peak area & \% Recovery \\
\hline \multirow{3}{*}{ CHLO } & 50 & 100 & 50 & 149.25 & 4660976.7 & 99.06 \\
\cline { 2 - 7 } & 100 & 100 & 100 & 200.92 & 6411781.3 & 101.20 \\
\cline { 2 - 7 } & 150 & 100 & 150 & 247.79 & 7965981 & 98.70 \\
\hline \multirow{3}{*}{ FLUR } & 50 & 6 & 3 & 8.99 & 1510256.3 & 98.20 \\
\cline { 2 - 7 } & 100 & 6 & 6 & 12.00 & 2089635 & 99.15 \\
\cline { 2 - 7 } & 150 & 6 & 9 & 14.89 & 2647795.3 & 98.24 \\
\hline
\end{tabular}

Limit of detection (LOD) and quantitation (LOQ)

The limits of detection and quantitation were found to be 1.05 and $3.18 \mu \mathrm{g} / \mathrm{mL}$ for Chloramphenicol and 0.075 and $0.23 \mu \mathrm{g} / \mathrm{mL}$ for Flurbiprofen sodium, respectively, indicating the sensitivity of the developed method.

\section{Robustness of the method}

The robustness of the method evaluated by assessing the effect of variations in method parameters on peak areas showed low RSD values (less than $2.0 \%$ ) indicating the robustness of the method (Table 6).

Table 6. Robustness of the developed HPLC method $(n=3)$

\begin{tabular}{|c|c|c|c|}
\hline Parameters & Drug & Mean area \pm SD & RSD \\
\hline $\begin{array}{c}\text { Mobile phase composition } \\
(+2 \mathrm{~mL})\end{array}$ & CHLO & $3021766 \pm 19228.03$ & 0.63 \\
\cline { 2 - 4 } & FLUR & $946076 \pm 8418.73$ & 0.88 \\
\hline $\begin{array}{c}\text { Mobile phase composition } \\
(-2 \mathrm{~mL})\end{array}$ & CHLO & $2970918 \pm 23765.87$ & 0.79 \\
\cline { 2 - 4 } Flow rate $(1.2 \mathrm{~mL})$ & FLUR & $944176 \pm 6722.63$ & 0.71 \\
\cline { 2 - 4 } & CHLO & $2972538 \pm 25688.99$ & 0.86 \\
\hline \multirow{2}{*}{ Flow rate $(0.8 \mathrm{~mL})$} & FLUR & $944146 \pm 8266.74$ & 0.87 \\
\cline { 2 - 4 } & CHLO & $947559 \pm \pm 30834.16$ & 0.86 \\
\hline
\end{tabular}

\section{Analysis of marketed formulation}

The marketed formulation, Flubichlor was analyzed using the developed method. The chromatogram of eye drops sample showed only two peaks at $R_{t}$ value of 1.980 min and 7.727 min for Chloramphenicol and Flurbiprofen sodium, respectively, indicating that there is no interference of the excipients present in the tablet formulation. The content of Chloramphenicol and Flurbiprofen sodium was 
calculated by comparing peak areas of the sample with that of the standard (Table 7).

Table 7. Assay results of the pharmaceutical dosage form $(n=5)$

\begin{tabular}{|c|c|c|c|c|}
\hline Drug & $\begin{array}{c}\text { Amount present per } \\
\text { 1 ml of solution }\end{array}$ & $\begin{array}{c}\text { \% Amount } \\
\text { found }\end{array}$ & SD & RSD \\
\hline CHLO & $5 \mathrm{mg}$ & $101.49 \%$ & 0.00827 & 0.16 \\
\hline FLUR & $0.3 \mathrm{mg}$ & $99.78 \%$ & 0.00032 & 0.10 \\
\hline
\end{tabular}

\section{Stability studies}

The results of the forced degradation study of Chloramphenicol and Flurbiprofen sodium using acetonitrile: water: glacial acetic acid (50:49:1 $v / v / v$ ) as the mobile phase system are summarized in Table 8.

Table 8. Summary of forced degradation studies of Chloramphenicol and Flurbiprofen sodium

\begin{tabular}{|c|c|c|c|c|c|}
\hline $\begin{array}{c}\text { Exposure } \\
\text { conditions }\end{array}$ & Drug & Time & \% Recovery & Degradation products (\%) & $\begin{array}{c}R_{t} \text { of degradation } \\
\text { products (min) }\end{array}$ \\
\hline \multirow{2}{*}{$\begin{array}{c}\text { Acid, } 0.1 \mathrm{~N} \\
\mathrm{HCl}, \\
\text { refluxed } \\
\end{array}$} & CHLO & $6 \mathrm{~h}$ & 83.26 & DP1 (11.53 \%), DP2 (5.53\%) & $2.547,2.760$ \\
\hline & FLUR & $6 \mathrm{~h}$ & 79.90 & DP1 (19.59\%) & 7.000 \\
\hline \multirow{2}{*}{$\begin{array}{c}\text { Base, } 0.1 \mathrm{~N} \\
\mathrm{NaOH}, \\
\text { refluxed }\end{array}$} & CHLO & $24 \mathrm{~h}$ & 97.34 & DP1 $(2.66 \%)$ & 2.527 \\
\hline & FLUR & $24 \mathrm{~h}$ & 99.48 & Not detected & - \\
\hline \multirow{2}{*}{$\begin{array}{c}\text { Peroxide } \\
(3 \%, v / v), \\
\text { refluxed }\end{array}$} & CHLO & $4 \mathrm{~h}$ & 77.62 & 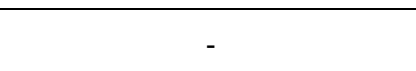 & - \\
\hline & FLUR & $4 \mathrm{~h}$ & 79.15 & - & - \\
\hline \multirow{2}{*}{$\begin{array}{c}\text { Dry heat } \\
\left(60^{\circ} \mathrm{C}\right)\end{array}$} & CHLO & $6 \mathrm{~h}$ & 80.46 & DP1 (19.22 \%), DP2 (0.2\%) & $1.413,2.540$ \\
\hline & FLUR & $6 \mathrm{~h}$ & 85.04 & DP1 $(14.58 \%)$ & 6.572 \\
\hline \multirow{2}{*}{ Photo } & CHLO & $4 \mathrm{~h}$ & 90.48 & DP1 (2.00 \%), DP2 (7.51\%) & $2.533,3.227$ \\
\hline & FLUR & $4 \mathrm{~h}$ & 99.13 & - & - \\
\hline
\end{tabular}

${ }^{*}$ DP1 and DP2 are the degradation products obtained in the forced degradation studies.

Acid-induced degradation study

Chloramphenicol and Flurbiprofen sodium, both were found to undergo acid degradation very rapidly. The reaction in $0.1 \mathrm{M} \mathrm{HCl}$ at $60^{\circ} \mathrm{C}$ under reflux for $6 \mathrm{~h}$ showed extensive degradation for chloramphenicol with additional peaks at
$\mathrm{R}_{\mathrm{t}}$ values of 2.547, 2.760 (about $11.53 \%, 5.34 \%$ degradation), respectively. For Flurbiprofen sodium, additional peaks were observed with $\mathrm{R}_{\mathrm{t}}$ values 7.000 (about 19.54\% degradation), respectively as shown in Figure 4, suggesting significant degradation of both drugs.

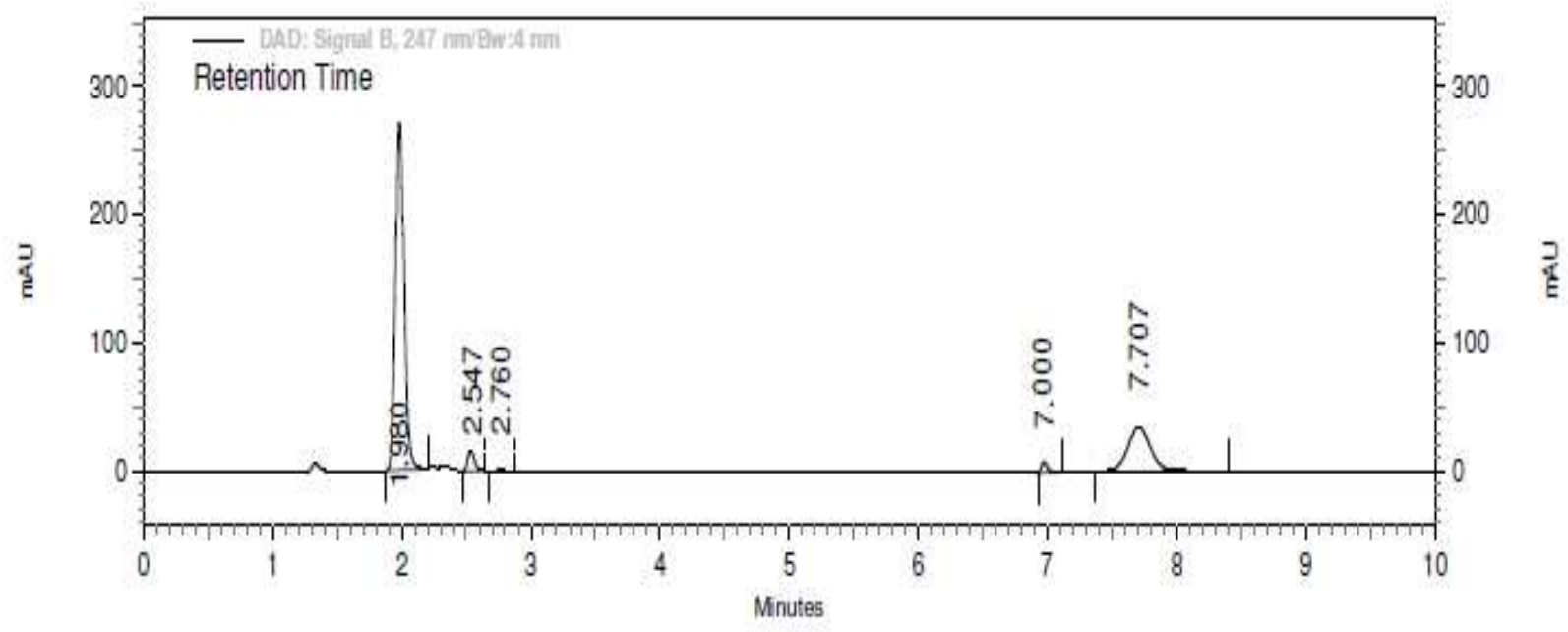

Fig. 4. Chromatogram of acid degraded Chloramphenicol and Flurbiprofen sodium 
Base-induced degradation study

In base induced degradation study, drugs did not show any additional peak other than the standard Chloramphenicol and Flurbiprofen sodium peak at $\mathrm{R}_{\mathrm{t}} 1.980 \mathrm{~min}$ and $7.693 \mathrm{~min}$ respectively. Drug recovery at the level of 97.34 $\%$ and $99.48 \%$ for Chloramphenicol and Flurbiprofen sodium respectively, suggested that the drug is stable toward the alkali as shown in Figure 5.

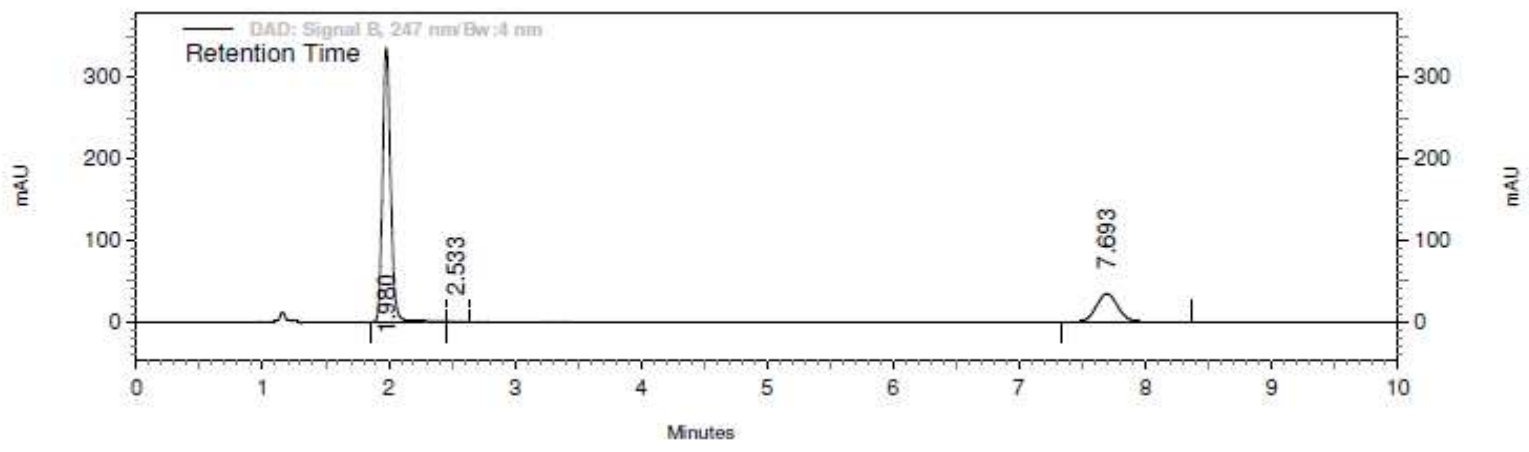

Fig. 5. Chromatogram of alkali degraded Chloramphenicol and Flurbiprofen sodium

\section{Oxidative induced degradation study}

In the oxidative degradation study, it was found that the area of the $\mathrm{H}_{2} \mathrm{O}_{2}$-degraded product peaks of Chloramphenicol and Flurbiprofen sodium was found to be extremely small than the area of standard drug concentration and drug recovery at the level of $77.62 \%$ and $79.15 \%$ for Chloramphenicol and Flurbiprofen sodium respectively suggest that significant degradation of both drugs in oxidative induced degradation. The chromatogram of peroxide degraded CHLO and FLUR is shown in Figure 6.

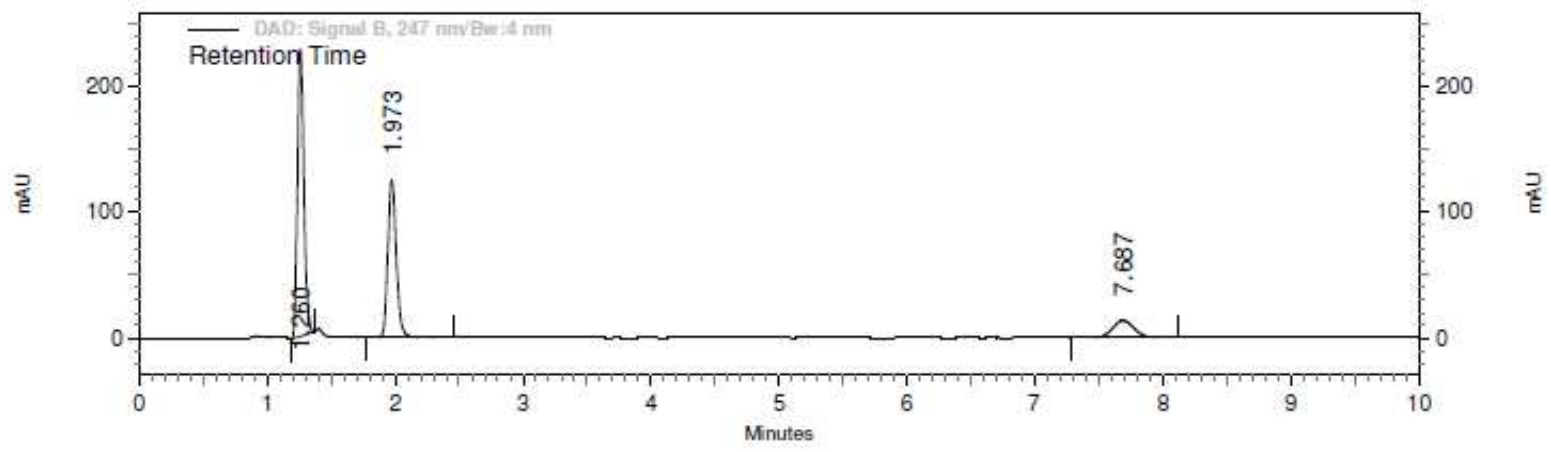

Fig. 6. Chromatogram of peroxide degraded Chloramphenicol and Flurbiprofen sodium

Thermal degradation study

In the heat degradation study, Chloramphenicol and Flurbiprofen sodium showed additional peaks at $\mathrm{R}_{\mathrm{t}}$ value at 1.413 (about 19.22\% degradation) and 6.687 (about $14.58 \%$ degradation), respectively as shown in Figure 7, suggesting significant degradation of both drugs in thermal degradation.

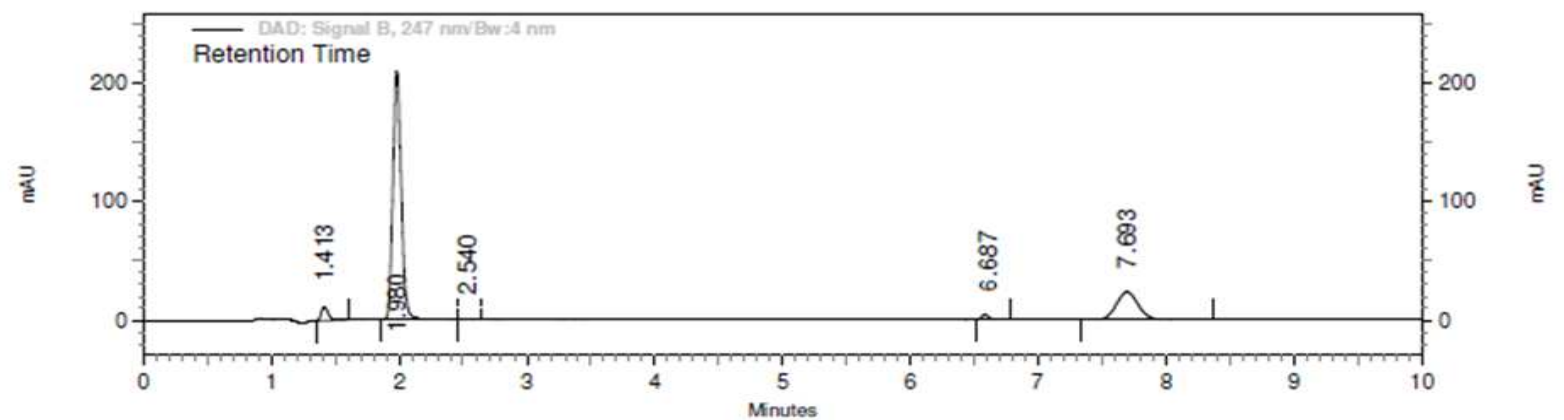

Fig. 7. Chromatogram of thermal degraded Chloramphenicol and Flurbiprofen sodium 


\section{Photo-degradation study}

In the oxidative degradation study, it was found that the area of the photodegraded product peaks of Chloramphenicol and Flurbiprofen sodium was found to be extremely small than the area of standard drug concentration and drug recovery at the level of $90.48 \%$ and $99.13 \%$ for Chloramphenicol and Flurbiprofen sodium respectively, suggesting the stability of FLUR toward photodegradation as shown in Figure 8.

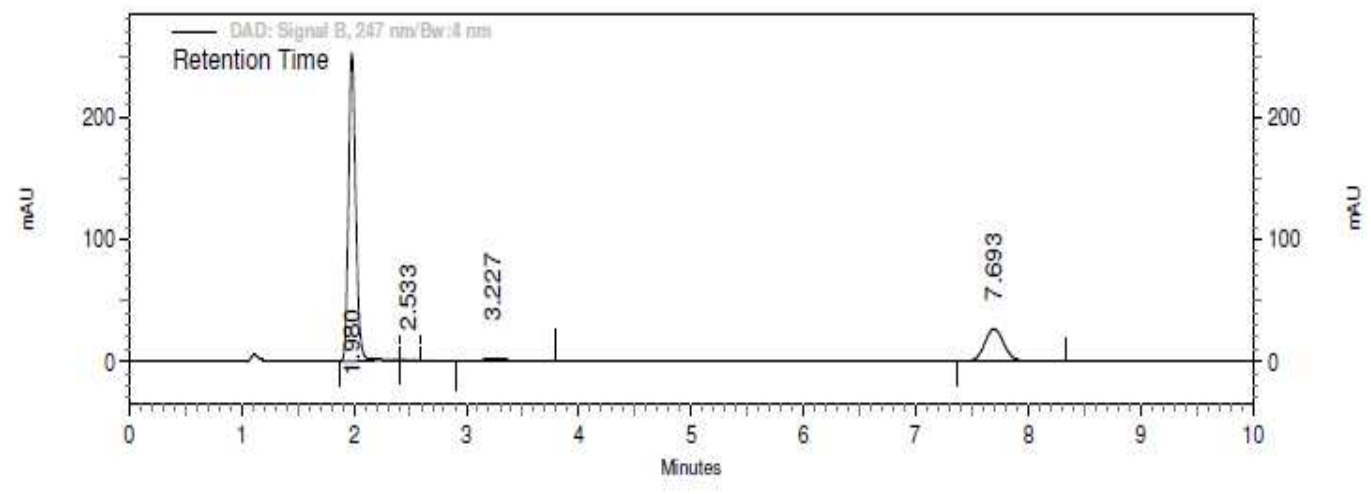

Fig. 8. Chromatogram of photo degraded Chloramphenicol and Flurbiprofen sodium

\section{CONCLUSION}

Stability indicating high-performance liquid chromatography (HPLC) method was developed and validated for the determination of Chloramphenicol and Flurbiprofen sodium in coformulations on HPLC column using acetonitrile: water: glacial acetic acid (50:49:1 $\mathrm{v} / \mathrm{v} / \mathrm{v})$ as the mobile phase with PDA detection at $247 \mathrm{~nm}$. The developed method was found to be simple, rapid, selective, sensitive and suitable for the simultaneous determination of Chloramphenicol (CHLO) and Flurbiprofen sodium (FLUR). The stability indicating properties established the

\section{REFERENCES}

Adewuyi GO, Olatoye OI, Abafe AO, Otokpa MO, Nkukut NK. High performance liquid chromatographic method for evaluation of two antibiotic residues in liver and muscle of broilers in Ibadan city, Southern Nigeria. J. Pharm. Biomed. Sci. 2011;11(11):1-4.

Akhlaq M, Khan GM, Wahab A, Khan A, Hussain A, Nawaj A, Abdelkader H. A simple high-performance liquid chromatographic practical approach for determination of flurbiprofen. J. Adv. Pharm. Tech. Res. 2011;2(3):151-5. [DOI: 10.4103/2231-4040.85529]

Chauhan CS, Singhvi I, Choudhury PK. Spectrophotometric determination of flurbiprofen sodium in biological fluid. Asian J. Chem. 2007;19(4):3286-8.

Dhavse VV, Parmar DV, Devarajan PV. High performance thin-layer chromatographic detection of flurbiprofen in plasma. J. Chromatogr. B. Biomed. Sci. Appl. 1997;694(2):449-53. [DOI: 10.1016/S0378-4347(97)000 46-7]

Hossain MA, Sayeed MSB, Haque MA, Dewan I, Ashraful Islam SM. Validation of RP-HPLC method for simultaneous determination of chloramphenicol and dexamethasone in eye drops. J. Adv. Pharm. Res. 2011;2(3):135-41.

ICH. Q2 (R1), Validation of Analytical Procedures: Methodology. International Conference on Harmonization, Geneva, 1996. following recommendations of ICH guidelines also indicated that the drugs could be evaluated in presence of their degradation products and thereby can be employed for the simultaneous estimation of Chloramphenicol and Flurbiprofen sodium and their degradation products in stability samples in the industry.

\section{ACKNOWLEDGMENTS}

The authors would like to thank Arihant School of Pharmacy and Bio-Research Institute, Gandhinagar, Gujarat, India for providing the necessary infrastructural facilities for this study.

Jagathi V, Rajesh V, Ramesh DB, Devalarao G. Thin layer chromatographic method for the determination of flurbiprofen. Res. J. Pharm. Bio. Chem. Sci. 2011;2(1):10810.

Katakam PK, Sireesha KR. Stability indicating HPLC method for simultaneous determination of chloramphenicol and prednisolone acetate in bulk and formulations. Asian J. Pharm. Clin. Res. 2012;5(3):182-5.

Katakam PK, Sireesha KR, Kumari AS. Stability indicating HPLC method for simultaneous determination of dexamethasone sodium phosphate and chloramphenicol in bulk and formulations. Int. J. Pharm. Pharmceut. Sci. 2012;4:505-10. [DOI: 10.5935/0100-4042.20140058]

Koup JR, Brodsky B, Lau A, Beam TR Jr. High-performance liquid chromatographic assay of chloramphenicol in serum. Antimicrob. Agents Chemother. 1978;14(3):439-43. [DOI: 10.1128/aac.14.3.439]

Li TL, Chung-Wang YJ, Shih YJ. Determination and confirmation of chloramphenicol residues in swine muscle and liver. J. Food Sci. 2002;67(1):21-8. [DOI: 10.1111/j.1365-2621.2002.tb11352.x]

Modi S, Chaudhary AB. Development and validation of stability indicating rp-hplc method for estimation of flurbiprofen sodium and chloramphenicol. World J. Pharm. Pharmaceut. Sci. 2017;6(10):1017-33. 
Pan C, Zhang H, Chen S, Xu Y, Jiang S. Determination of chloramphenicol residues in honey by monolithic column liquid chromatography-mass spectroscopy after use of quenchers clean-up. Acta Chromatogr. 2006;17:320-7.

Patel G, Chauhan AK, Shah S. Simultaneous estimation of gatifloxacin and flurbiprofen sodium in ophthalmic formulation by UV-specrophotometric method. J. Chem. Pharm. Res. 2013;6(7):96-101.

Rajani B, Bangar Raju B, Mukkanti K. Method development and validation for estimation of flurbiprofen in tablet dosage form by liquid chromatography. Int. J. Pharm. 2014;4(1):309-12.

Rimawi FA, Kharoaf MS. Analysis of chloramphenicol and its related compound 2-amino-1-(4-nitrophenyl) propane-1, 3-diol by reversed-phase high-performance liquid chromatography with UV detection. Chromatogr. Res. Int. 2011;2011:1-6. [DO I: 10.4061/2011/482308].

Sanjeev C, Jadhav PR, RaviShankar D, Saha RN. Determination of flurbiprofen in pharmaceutical formulations by UV spectrometry and liquid chromatography. Anal. Chim. Acta 2002;463(2):207-17.

Tamosiunas V, Petraitis J, Padarauskas A. Chloramphenicol determination in milk by liquid chromatography-tandem mass spectrometry. Chemija 2006;17(2-3):25-9.

Wang WS, Hsu TY, Hsu P, Chang ST, Shih CW. Simultaneous determination of chloramphenicol, florfenicol, and thiamphenicol in tilapia tissues by HPLC. J. Chin. Soc. Vet. Sci. 2001;27(3):221-31. 